\title{
POR UMA REFUNDAÇÃO MACROPOLÍTICA DO SUS: A GESTÃO PARA A EQÜIDADE NO COTIDIANO DOS SERVIÇOS*
}

\author{
Paulo Eduardo Mangeon Elias**
}

\begin{abstract}
RESUMO: O autor pontua a necessidade de diálogo entre a Academia e as outras instituições e faz um esforço para partir de um plano mais teórico em relação à questão da equidade e da gestão para chegar ao plano dos serviços. É feita uma diferenciação entre gestão e gerência. Apesar da raiz comum destas palavras não se deve imaginar que ao resgatá-las para a política que elas têm que ser tratadas separadamente. Elas não devem ser tratadas separadamente, mas apresentam nuances, significados e instâncias diferentes. Há indicação de alguns requisitos macro-políticos necessários para propiciar o encaminhamento proveitoso e fecundo das idéias apresentadas. $O$ autor finaliza sua apresentação com um elenco de possíveis repercussões deste ideário no plano dos serviços, isto é no âmbito mais imediato da prática cotidiana dos profissionais de saúde.
\end{abstract}

PALAVRAS-CHAVE: gestão, política, eqüidade, organização de serviços, SUS

\footnotetext{
* Apresentado na Mesa Redonda Gestão da Saúde para a Eqüidade, em 02/10/01, VII Congresso Paulista de Saúde Pública. ** Professor da Faculdade de Medicina da Universidade de São Paulo.
} 


\section{INTRODUÇÃO}

Inicialmente agradeço à Associação Paulista de Saúde Pública, na figura de seu Presidente Paulo Fernando Capucci, pelo convite que muito me honra. Agradeço também à Comissão Científica na figura do Professor Marco Akerman. Estou muito satisfeito de aqui estar, e inicio as minhas considerações inspirado pelo final da palestra do José Ênio, ao indagar quem seria ele para fazer sugestões à Academia. Pois respondo que ele é muita gente e me sinto privilegiado pela oportunidade de com ele dialogar nesta Mesa.

É preciso desmistificar a questão da Academia, no sentido de questioná-la enquanto 'torre de marfim'. A Academia é uma instituição semelhante a muitas outras, tais como àquelas que se dedicam ao 'fazer' atendendo e prestando serviços à sociedade. Reafirmo que estas instituições são tão importantes quanto a Academia, mas respondo ao questionamento do Ênio afirmando que a Academia continuará elucubrando, no sentido de formular um pensamento crítico como expressão da autonomia intelectual de seus autores. A meu ver esse é o papel da Academia e de resto não deveria ser outro.

A novidade é a necessidade de diálogo entre a Academia e as outras instituições, sem que nenhuma delas perca as suas identidades, porque a virtude não está na perda da identidade mas no estabelecimento de diálogo mantidas as identidades.

Portanto, para não fugir à regra, vou me permitir aqui ao exercício de elucubrar, no sentido que estou dando para esta palavra. Farei um esforço de sair de um plano mais teórico e tentar chegar ao dos serviços. Vejamos se consigo realizar isso com algum sucesso pois esse será o meu esforço.

\section{ESFORÇO DE PARTIDA: DA TEORIA AOS SERVIÇOS}

Principio apontando que a articulação entre os termos gestão e eqüidade não é natural e nem sequer simples. Isto faz com que se perceba algumas dificuldades, isto porque são termos com origens teóricas e conceituais bastante distintas. A dificuldade maior está pelo lado da eqüidade e a menor pelo lado da gestão.

Quem faz uma revisão da literatura sobre o termo eqüidade vai ver a particularidade 
com que esse termo é tomado na área da Saúde, e eu, provisoriamente e de uma forma talvez não muito elegante, diria que esse termo freqüentemente recebe um tratamento econométrico pela área da saúde, no sentido de buscar quantificá-lo.

No entanto, este termo não se presta enquanto conceito a essas medições. Quando você vai olhar a produção da área de Ciências Humanas, você vê o contraste entre esses dois tipos de abordagem. Este é o primeiro assinalamento que registro. Em segundo lugar, a eqüidade é um conceito não bem estabelecido e de difícil operacionalidade, cabendo uma segunda advertência: qualquer conceito é difícil de ser operacionalizado, porque conceitos não são elementos do mundo das coisas, eles são elementos do mundo das idéias, portanto há uma dificuldade em se operar qualquer conceito e esse em particular penso ser ainda mais complicado.

É que, como nos ensina Antonio Geraldo da Cunha, a própria raiz etimológica da palavra indica distintas origens e possibilidades de distintos sentidos. Termo latino que significa igual, plano, liso, justo; sublinho o significado justo que já se documenta em vocábulos formados no próprio Latim, como eqüidade, e alguns outros introduzidos em outras línguas cultas: no Grego, no Inglês, no Francês e no Alemão.

$\mathrm{Na}$ modernidade o termo foi retomado na língua portuguesa por volta de 1813. Na tradição filosófica, o conceito clássico, tal qual esclarecido por Aristóteles e reconhecido pelos juristas romanos, o sentido indica o apelo à justiça enquanto voltado à correção da lei em que se exprime a justiça. Diz Aristóteles que a própria natureza da eqüidade é a retificação da Lei onde esta se revela insuficiente pelo seu caráter universal. A Lei tem necessariamente caráter geral, por isso revela-se às vezes de aplicação imperfeita ou difícil em casos particulares.

Nestes casos, isto é, nos particulares, a eqüidade intervém para julgar, não na base da Lei mas na base da justiça que a mesma Lei deve realizar. Portanto, segundo Aristóteles, o justo, o eqüitativo, são a mesma coisa, podendo se inferir que o eqüitativo é superior, não ao justo em si mas, ao justo formulado em uma Lei que em a virtude da sua universalidade está sujeita ao erro.

$\mathrm{Na}$ tradição filosófica moderna, fundamentando-se em conceito análogo ao aristotélico, Kant considerava, todavia, que a eqüidade não se presta a uma autêntica reivindicação jurídica, e que portanto cabe não aos tribunais, mas ao tribunal da consciência. 
Vejam, a gênese da eqüidade como uma questão jurídica e depois conceituada ou reconceituada como uma questão moral e seus desdobramentos para a área da Saúde.

Desta forma nós já começamos a ver as dificuldades que estão postas, e os desafios a serem enfrentados. Assim são perfeitamente inteligíveis as deficiências em relação aos marcos conceituais da eqüidade referida à área da Saúde. Porém, ela deve ser estabelecida como uma noção orientadora e imprescindível para um país como o Brasil. Não é se justifica que as deficiências teórico-conceituais impeçam que a adotemos como noção orientadora, como um norte a ser seguido nas políticas de saúde e na prática dos serviços.

De certo modo, a noção de equidade se associa de modo diverso à igualdade e sobretudo à justiça, no sentido de propiciar a correção daquilo em que a igualdade agride e portanto naquilo que a justiça deve realizar. Esse é o sentido e, vejam, a eqüidade não deve trabalhar com a igualdade, pois ela é a corretora da igualdade.

Estas noções têm implicações em processos na área da saúde, tais como o da descentralização, cujo fundamento é a igualdade. Não se trata, evidentemente, de rejeitar a descentralização, ao contrário temos que afirmá-la, mas temos que entender também as dimensões de suas insuficiências.

Como bem disse aqui o José Ênio, com o qual concordo, a descentralização é uma diretriz muito importante, no entanto ela contém insuficiências. Já o termo gestão tem origens e apropriações muito diversas. Gestão ou gestatório, deriva do verbo latino gerire, apresentando como significados administrar, dirigir e, sublinho, regular.

Regular é a raiz da qual deriva gerência, gerenciar e gerentes, termos disseminados na língua portuguesa em fins do século XIX e início do século XX. Da raiz latina gestil, ação de dirigir, gerência, administração, como usada por Cícero, o grande orador romano, deriva o termo gestão, usado na língua portuguesa a partir de 1858, apropriado pela disciplina de Administração e disseminado no século $X X$ vinculado a essa matriz. Portanto trata-se de uma matriz administrativa.

Resgatar a Gestão para a matriz política implica, antes de tudo, desvinculá-la dos marcos utilitaristas do mercado, (custo/benefício, custo/efetividade), reposicionando-a, por referência, às concepções teleológicas que informam a Gestão, isto é, como se concebe o que fazer. A concepção é muito importante e a direcionabilidade também o é por implicar o que fazer. 
Tal concepção requer um determinado diagnóstico, entendido como construção da realidade, pois a realidade não está dada, a realidade é construída a partir de determinados parâmetros referidos às necessidades, ou seja, para quê finalidade se destina. Portanto exige que se pense o para quê, a partir de um diagnóstico a quê finalidade a intervenção se destina. A reconstrução da realidade deve ser realizada segundo esse parâmetro, o quê se quer. Ela não é dada naturalmente, como pensam os positivistas, que a natureza está dada e só temos a tarefa de deslindá-la. Não é assim, ela é construída, e essa construção é essencialmente subjetiva, e se fundamenta em referenciais abstratos que são importantes.

Por isso assinalo a pertinência e a exigência da concepção de como se concebe, e propugno o abandono do marco utilitarista em voga, que aponta como sendo moderno a gerência e o gerenciamento nesse marco econômico, no marco de mercado.

Portanto, resgatar a gestão para a política significa indagar sobre as concepções que informam o quê fazer, e para quê ou para quem se destinam o fazer. Já o como fazer se refere aos meios utilizados, e nesse sentido diz respeito à instância gerencial do processo ou, como se costuma nominar, à sua dimensão mais propriamente tecnológica.

\section{GESTÃo E GERÊNCIA NO PLANOS DO SERVIÇO}

Principio a minha abordagem pela diferenciação entre gestão e gerência. Apesar da raiz comum destas palavras não se deve imaginar que ao resgatá-las para a política que elas têm que ser tratadas separadamente. Elas não devem ser tratadas separadamente, mas apresentam nuances, significados e instâncias diferentes.

Para fins dessa apresentação, gestão do sistema refere-se à articulação público/ privado, que estrutura e regula o sistema de saúde, enquanto que modalidade de assistência significa as maneiras de se organizar os serviços de assistência à saúde, que configuram os chamados modelos assistenciais e cujo núcleo principal reside na organização do processo de trabalho.

Na realidade tenho uma certa implicância com o termo modelo assistencial, aliás uma grande implicância, que sublinho sem contudo poder desenvolver hoje. Um aspecto deste assinalamento se refere ao sentido de modelo, pois prefiro o termo modalidades 
assistenciais e não modelos assistenciais. Até pela potencialidade despolitizadora que o termo traz, enquanto modelo já dado, acabado, e passível de reprodução e de cópia. Tal postura estiolaria a criatividade e a exigência de criatividade que se tem ao tratar dos processos.

Portanto, gestão diz respeito às formas e modos de regulação e produção de serviço de saúde, a partir das duas principais modalidades de regulação vigentes nas sociedades capitalistas: a perspectiva de mercado, otimizadora da eficácia locativa custo/benefício, e a do Estado, otimizadora da eficácia eqüitativa, da justiça, portanto.

Parte-se do pressuposto de que a atuação na modalidade gestão constitui o foco privilegiado para uma intervenção eficaz no redirecionamento do SUS, pois é ela que conforma as possibilidades para estruturação das modalidades de assistência à saúde e não o inverso, como freqüentemente se sugere. É a gestão que conforma as modalidades de assistência à saúde e não o inverso.

Durante muito tempo discutimos as modalidades assistenciais não percebendo a sua relação com a gestão. O redirecionamento do SUS para fazer frente ao principal problema social brasileiro representado pela exclusão de amplos setores da população, requer mudanças de distintas ordens, abarcando os planos macro e micropolíticos, dentre esses, a modalidade de gestão vigente no SUS, bem como a maneira de se organizarem os serviços de saúde.

Em termos gerais tais mudanças devem rejeitar o modelo burocrático de gestão, caracterizado, dentre outros aspectos, pelo grande número de estruturas intermediárias decisórias, o controle político exercido através da estrutura administrativa hierarquizada e a diluição da responsabilidade político-administrativa.

Devemos incentivar as modalidades de gestão mais flexíveis, mais ágeis, nas quais impere a autonomia administrativa e gerencial no serviço de saúde aliada à responsabilidade dos quadros dirigentes dos serviços e ao desenvolvimento de instrumentos específicos de controle e avaliação de desempenho na prestação de assistência e no atendimento dos parâmetros da política de saúde estabelecida, a serem operadas nos níveis mais descentralizados.

Esta postulação pretende rejeitar o modelo burocrático e administrativo vigente que conspira contra o SUS, pois o poder de controlar deriva da hierarquia administrativa e não 
da informação e dos instrumentos de avaliação. A organização dos serviços de saúde deve pautar-se na maior integração possível do trabalho dos diversos profissionais, tendo como balizamento a sua potencialização, em benefício dos usuários dos serviços e na inversão da lógica clássica da sua estruturação, esta voltada para os interesses endógenos do serviços e expressos pelos vários profissionais que o compõem.

Os serviços devem pautarem-se por uma lógica socialmente virtuosa ao submeter os interesses endógenos do serviço aos interesses dos usuários deste mesmo serviço.lsto significa conceber o serviço de saúde não como um fim em si, como classicamente vem ocorrendo, mas sim como um meio de atender as necessidades sociais, estas expressas mais imediatamente pelas demandas da população assistida.

Por fim, o sistema de saúde como um todo deve pautar-se pela lógica da eficácia social e da racionalidade, tendo por diretrizes a descentralização administrativa, gerencial e financeira no que couber aos serviços de saúde e ficando a formulação da política de saúde para o nível distrital; a integração horizontal entre os serviços de mesmo nível de assistência ( atenção ambulatorial, serviços de apoio diagnóstico e terapêutico, Programa de Saúde da Família) e a integração vertical entre os diferentes níveis de assistência (atenção primária, secundária e terciária) e o desenvolvimento de tecnologias para o gerenciamento da prestação da assistência.

\section{REQUISITOS MACRO-POLÍTICOS PARA ENFRENTAR A EXCLUSÃO E DESIGUALDADE}

Isto posto, é necessário indicar alguns dos requisitos macro-políticos necessários para propiciar o encaminhamento proveitoso e fecundo dessas idéias apresentadas. Antes, porém, quero apresentar uma advertência importante: a de que as modalidades assistênciais e os sistemas de saúde estrangeiros não nos servem para serem copiados mas sim para nos inspirar, pois nós brasileiros vamos ter que pensar as soluções para os nossos problemas.

Portanto, rejeito esse modismo e a crítica que está posta na Europa, pois eles lá têm outros problemas de saúde mas de certo modo as soluções e encaminhamentos estão sendo trazidos para cá de uma maneira completamente acrítica. Por exemplo, a crítica centrada nos modelos hierarquizados, como o adotado pelo sistema nacional de saúde inglês, apresentada como se ele estivesse ultrapassado, quase uma evocação do passado, 
em prol das modalidades vigentes principalmente nos Estados Unidos da América do Norte, da atenção gerenciada, como sendo a expressão acabada da modernidade. Este embate, sobre o qual não tenho tempo para tratar neste momento, merece este assinalamento uma vez que sou dos que não vão a entrada destes modismos pelas portas do fundo do debate intelectual, travestidos de modernidade, o que de resto não se apresentam pelo simples fato de não atenderem aos nossos problemas atuais.

No plano macro-político, o combate à desigualdade, à exclusão social em prol da efetivação da saúde como direito social no cotidiano dos cidadãos requer medidas diversas que compõem uma agenda pra transformação, devendo contemplar os seguintes aspectos, os quais pretendo tratar rapidamente para não ultrapassar o tempo que me resta:

A rejeição absoluta ao discurso da globalização dos problemas e das soluções, ao qual fiz referência acima, como ditames dos ' modismos ideológicos' e imposição das agendas das agências internacionais multilaterais de fomento econômico. E mais uma vez cabe advertir que não pretendo transformá-las em demônios que não são, porque quem opera este ideário aqui no Brasil são brasileiros, pois elas não têm condições de operar sem a intermediação de brasileiros. Portanto não se trata de interpreta-las como criaturas do demo, mas devemos com elas dialogar, buscando o que nos interessa, o que desejamos, e rejeitar aquilo que não nos interessa.

A melhoria dos mecanismos de governabilidade, sobretudo no que diz respeito ao pacto federativo e ao estabelecimentos de bases concretas, isto é, o arcabouço jurídico e administrativo condizentes, para o desenvolvimento de formas efetivas e estáveis de cooperação entre Estados e Municípios. Sem poder estender em demasia este comentário para não ultrapassar em demasia o meu tempo quero assinalar que não temos ainda estes mecanismos estabelecidos de forma apropriada.

Promover, a desmercantilização da produção dos serviços de saúde, o que implica o estímulo à produção privada de serviço sob modalidades não mercantis. Este aspecto é significativamente importante e claro está que também devemos estimular também a produção de serviços de saúde pelo Poder Público também, mas me interessa chamar a atenção para produção privada deste serviços mas não nas formas mercantis formas mercantis como temos hoje.

O estabelecimento das políticas de saúde como políticas de Estado, ou seja, que ela se constituam imunes em suas estruturas às naturais instabilidades da alternância de 
governos. A recusa à partidarização da saúde, no sentido do loteamento dos cargos da Saúde em benefício de uma organicidade eleitoral de agrupamentos de interesses geralmente paroquiais, que afrontam as necessidades sociais do setor. Neste ponto não posso deixar de assinalar que a patidarização da saúde encontra-se disseminada entre nós, abrangendo todo o espectro político brasileiro - da esquerda à direita - apenas apresentando variação no grau e na forma como se apresenta mas preservando a sua natureza. Este procedimento é uma praga social que exige ser apontada e combatida.

A orientação, ou reorientação do processo de descentralização para potencializar a democratização das ações de saúde, considerando-se que o tratamento dos problemas a partir do Município favorecem a integração das políticas públicas de desenvolvimento urbano e que possa contemplar também essa reorientação a responsabilização solidária entre os três níveis de governo na sua efetivação. Deste modo se pretende impugnar a prática de se "empurrar abacaxis de cima para baixo", pois obviamente isto não vai levar a bom termo coisa nenhuma, na perspectiva aqui colocada.

A articulação da razão econômica com as necessidades sociais no manejo orçamentário, possibilitando um processo contínuo e estável de inclusão social.

A implementação de mecanismos de controle social que promovam a disseminação das informações de interesse público, como forma de fortalecer oprocesso de decisão dos cidadãos.

O desenvolvimento de um processo de descentralização e reorganização do sistema de saúde em bases microregionais e regionais, que contemplem a intersetorialidade e a integração das políticas públicas governamentais e não governamentais do setor saúde.

O estabelecimento de um pacto nacional a partir da Emenda Constitucional, de vinculação das receitas federais, estaduais e municipais da saúde, a famosa PEC ou Emenda Constitucional 29, capaz de garantir um financiamento das ações e serviços de saúde, como foi apresentado pelo José Ênio.

A ampla reforma administrativa do Estado, orientada para a maximização da eficácia social da ação estatal, em detrimento do modelo burocrático vigente, centrado no controle formal e nos procedimentos meios. A atual forma de organização administrativa do Estado brasileiro conspira contra o SUS e o inviabiliza da perspectiva que estou colocando. Não propriamente por ser público, isto é administração pública direta mas pela forma como ela 
está estruturada e organizada. Há um requisito inadiável por se realizar a reforma do Estado brasileiro.

No plano micro-político o rol de mudanças deverá contemplar uma série de ações tais como:

- Enfatizar a busca de formas alternativas de gestão na área da Saúde, como possibilidade de reinventar as formas de relação entre o Estado e a sociedade no atendimento de necessidades sociais. Não há uma única forma de gestão para o SUS, uma vez que o SUS é constituído de princípios e diretrizes. De modo que as formas operacionais têm que ser orientadas de maneira a atender os sete ideários aqui expressos.

- Temos que buscar o deslocamento da persistência de um padrão de modelo assistencial como fundante do verdadeiro SUS, em benefício do incentivo à criatividade nas instâncias gestoras dos serviços para o encaminhamento das necessidades da população, resguardando os princípios constitucionais da saúde. Neste particular, vale mencionar a adoção do Programa de Saúde da Família como modalidade estruturante do sistema de saúde. Não se trata do PSF em si mas sim de suas potencialidades, o que depende de como o ele será peracionalizado.Estou salientando também que se vicejem possibilidades de modalidades assistenciais várias, porque as necessidades e os requisitos desse País continental são significativamente diferentes e não podem estar padronizada,estandardizada por apenas uma modalidade de gestão ou de assistência.

- Descentralizar o planejamento da saúde no nível regional e distrital, com ênfase na população, o que implica a consideração dos deslocamentos dos contingentes populacionais em função do trabalho, e o dimensionamento da capacidade real de produção de serviços com vista à adscrição de clientela. À população descoberta de serviços deverá constituir-se em um objeto privilegiado do planejamento, com vista a se buscarem soluções flexíveis, ousadas e criativas, portanto em contraposição ao ponto de vista da ortodoxia conceitual, capazes de responderem transitoriamente às demandas da população por serviços de assistência médica. Trata-se de ser flexível e criativo mesmo sabendo ser uma intervenção transitória, pois o aspecto central é o de colocar os meios a serviço dos interesses da população e não defender os princípios como principismos que ofendem e dificultam a realização desses interesses.

- Efetivar a máxima autonomia administrativa e de organização do processo de trabalho nas unidades produtoras de serviços de saúde, de modo a observar o estrito 
compromisso com os resultados sociais, isto é o impacto social do trabalho realizado.

- Finalmente, implementar um processo gerencial fundado na estruturação de sistemas de informação orientados para o gerenciamento da Saúde, concebido segundo o ideário aqui expresso e não nos parâmetros do mercado.

\section{A TíTULO DE FINALIZAÇÃo}

Para evitar alongar em demasia o tempo disponível, vou somente elencar as repercussões deste ideário no plano dos serviços, isto é no âmbito mais imediato da prática cotidiana dos profissionais de saúde.

A organização do processo de trabalho, tem que ser pensada segundo os seus requisitos técnicos mas esta organização tem que ser socialmente orientada, isto é para quê e não orientada por princípios abstratos; é claro que toda organização do trabalho funda-se em princípios, mas o que assinalo é a relevância de ela ser socialmente orientada.

O processo de trabalho não está dado, ele necessita ser pensado e organizado a partir de determinadas indagações prévias, tais como, para quê e para quem, e o quê que se pretende realizar. O processo de trabalho não se resume a dimensão técnica em si, ele é um meio para algum fim, portanto tenho que indagar do fim para construir o meio, me socorrendo dos instrumentais técnicos. E qualificação técnica é indispensável, não se faz bom serviço de saúde sem qualificação técnica.

No que toca às exigências administrativas dos serviços, elas também tem que ser pensadas do ponto de vista da eficácia social, isto é que tipo de restrição social elas operam. Assim as exigências para marcação de retornos, exames, tudo isso tem que ser pensado do ponto de vista da eficácia social, pois elas constituem meios para determinados fins e é neste processo que se explicita o compromisso social e as finalidades dos serviços de saúde. Este compromisso social não é natural e nem dado e não são os parâmetros técnicos que o definem pois a técnica é meio e não fim. Trata-se de inverter a lógica dos serviços, transformá-los em pró-ativos, referidos aos interesses dos usuários e não dos endógenos e corporativos. 
Em relação aos recursos humanos, devemos resgatar as noções de responsabilidade social, compromisso, e a de ser funcionário público, pois estas noções foram perdidas nos anos 90 e os governo as jogaram na lata do lixo. Eu não posso deixar de registrar a minha grande decepção em relação ao Professor Fernando Henrique Cardoso, pois com a sua biografia e trajetória, permitiu que em seu governo continuasse a ser jogadas na lata do lixo noções tão caras como a de funcionário público e serviço público. Isto não posso deixar de registrar e não tem nenhum sentido ideológico, nenhum sentido de ranço ideológico ou partidário mas expressa uma decepção profunda de quem trabalha na universidade. Portanto, temos que imaginar que o funcionário público é um instituinte da cidadania e não um mero trabalhador da saúde; ele é mais do que um trabalhador da saúde e sem pessoal não se muda e transforma o serviço de saúde.

Para encerrar advirto que uma operação política necessária à condução de uma agenda de tal magnitude não é tarefa para parcelas da sociedade, sejam elas partidos ou movimentos sociais, ao contrário, supõe a construção de bases as mais amplas e sólidas possíveis, portanto, para além dos interesses político-partidários e ideológicos mais imediatos, bases essas capazes de aglutinar todos os setores sociais preocupados com a superação da exclusão social. Todos são bem-vindos, todos são necessários, pois necessitamos de base social para realizar essas transformações que são inadiáveis num País que se destaca na exclusão social.

\title{
TOWARDS A MACROPOLITICAL REFOUNDATION OF SUS: THE MANAGEMENT FOR EQUITY IN THE ROUTINE OF HEALTHCARE DELIVERY
}

\begin{abstract}
The author points out the need of dialogue between the academia and other institutions and makes an effort to start from a more theoretical level related to equity and management to achieve the healthcare delivery level. A differentiation between management and administration is made.

Although these terms have a common root, when rescued to politics one should not treat them separately. They should not be independently dealt with despite their different nuances, meanings and institutions. There is indication of some macro-political requirements needed to refer the ideas presented in a fruitful and productive fashion. The author ends his presentation with a list of possible repercussions of this set of ideas at healthcare delivery level, that is, within the most immediate scope of the daily practice of healthcare professionals.
\end{abstract}

KEYWORDS: management; politics; equity; organization of services, SUS. 